\title{
Chapter 3 \\ Physical Environment of Tall Residential \\ Buildings: The Case of Hong Kong
}

\author{
Stephen S.Y. Lau
}

\subsection{Introduction}

Increasing urban populations, scarcity of urban land, depletion in resources and severe impact of urban development on sustainability are critical contemporary issues. Such issues have vast implications on the desirability of compact, highrise high-dense built forms. Yet, the environmental quality and social acceptance of these forms remain barely studied. This chapter reviews some of the critical environmental implications posed by the closely packed high-rise building and high urban densities. High-rise buildings of Hong Kong ${ }^{1}$ are explored to discuss the pressing challenges of poor air quality, ventilation, daylight, lack of open space and noise pollution. Both quantitative and qualitative appraisals of Hong Kong residents living in high-rise buildings are used to analyse the environmental challenges. Recommendations for improvements using current practices in Hong Kong and possible solutions for the future are also discussed.

\subsection{Urban Morphology and Its Implications: The High Rise, High Density Compact Setting}

Urban morphology is the study of the physical form of a city. Broadly, such study would consider the street patterns, building sizes and shapes, architecture, population density and patterns of residential, commercial, industrial and other uses, among other things. Special attention is given to how the physical form of a city changes over time and how different cities can be compared with each other. Related

\footnotetext{
S.S.Y. Lau $(\varangle)$

Department of Architecture, The University of Hong Kong, Pokfulam, Hong Kong e-mail: ssylau@hku.hk; laustephensy@gmail.com

${ }^{1}$ Hong Kong is used as an example for the study because its choice of an urban form is seen to create a major influence on numerous Chinese cities.
} 
to the physical form, urban morphology would also study social forms, which are expressed in the physical layout of a city, and conversely, how physical form produces or reproduces various social forms.

Urban morphology is at times considered as the study of urban fabric, as a means of discerning the underlying structure of the built landscape. This approach challenges the common perception of unplanned environments as chaotic or vaguely organic through an understanding of the structures and processes embedded in urbanization. It is widely accepted that there is a close relationship between shape, size, density and uses of a city and the sustainability of that city. However, this chapter is limited to the characteristics of a high-rise, high-density compact urban environment: Hong Kong and its environmental implications.

It is said that urban intensification creates frequent walking trips and better accessibility to facilities (Masnavi, 2000). In a compact city the reduction in car ownership, vehicular trips and increase of pedestrian and transit use alleviate the environmental consequences associated with the automobile. Compact city has many advantages such as conservation of countryside, reduced need to travel by car and thereby reduction in fuel and pollution, support for public transport, walking and cycling, better access to services, more efficient utility and infrastructure provisions, and revitalization and regeneration of urban areas (Burton, 2000). In contrast to compact city, dispersed cities suffer from inefficient transport management and long commuting trips, which lead to a high dependency on automobile high energy consumption and pollution (Newman \& Kenworthy, 1992).

Although high density combined with mixed use allows for high accessibility to a majority of users, the mixing and co-location of incompatible uses such as housing, community, recreational and public spaces near commercial, industrial and transport can have consequences on the physical quality of the living environment. Greater intensification has implications on urban green space. Even though a valuable contributor to urban quality, urban greenery provision is often reduced under pressure from other land use development. Research claims that compact city suffers from a perceived lack of greenery, open spaces and parks which provision is seen to be better in low-density environment (Masnavi, 2000).

However, urban sprawl results in unsustainable levels of resource use and inequitable lifestyles (Williams, Burton, \& Jenks, 2000). In comparison with urban sprawl, the compact city is a dominant model for sustainability (Jenks, 2000). Yet, evidence on the impact of higher and lower densities on sustainability, the impact of centralized decentralized city form on sustainability are lacking. Review of some city forms indicates both advantages as well as disadvantages in sustainability. For example, forms that reduce travel and are fuel-efficient may be harmful to the environment and have social inequities. They may be locally beneficial but not city-wise beneficial (Williams et al., 2000). The effects of urban density on the total energy demand of a city are complex and at times conflicting (Givoni, 1998). Compactness of land use patterns will bring benefits to energy distribution and transport system design, but crowded conditions may create congestion and undesirable local microclimate (Hui, 2000). The compact city challenges are mainly associated with environmental quality and social acceptability (Williams et al., 2000). 


\subsection{A Compact City: Case of Hong Kong}

A multiple intensive land use development in Hong Kong is formed by an intensification of land use through mixing residential and other uses at higher densities at selected urban locations, together with an efficient transport and pedestrian network (Lau \& Coorey, 2007; Lau, Ghiridharan, \& Ganesan, 2003). Hong Kong is one of the Asian cities that have evolved as a compact urban form. Situated at the south-eastern tip of China, Hong Kong is ideally positioned at the centre of rapidly developing East Asia. With a total area of 1,103 $\mathrm{km}^{2}$, it covers Hong Kong Island $\left(80.41 \mathrm{~km}^{2}\right)$, the Kowloon peninsula just opposite $\left(46.93 \mathrm{~km}^{2}\right)$, and the more rural section of Hong Kong New Territories and 262 outlying islands $\left(976.38 \mathrm{~km}^{2}\right)$. The central part of both Hong Kong Island and Kowloon are hilly rising to a height of $3,050 \mathrm{~m}$. Only $21.8 \%$ of Hong Kong land is built up, concentrating on the triangular tip of Kowloon and the coastal strip of northern Hong Kong Island.

The total population in Hong Kong is 6,864,346 with the median age rising from 30 in 1988 to 36 in 2006 (Census and Statistics Department, 2006). The median monthly household income is $\mathrm{HK} \$ 15,000$. A population growth rate of approximately 1 million is observed in every 10 years in the last decade and the population forecast for 2,030 is 9 million (Fung, 2001). Although the total population density is 6,380 persons per $\mathrm{km}^{2}$, urban areas hold a staggering population density of over 55,000 persons per $\mathrm{km}^{2}$ where certain districts rank among the most densely populated places in the world. The density of public housing reaches at least 2,500 residents per ha, which is twice the density of the most crowded residential areas in mainland China (Xue, Manuel, \& Chung, 2001). High-density in a land limited country like Hong Kong is the norm. Cities often respond to development pressure by setting targets for increased urban densities, and the establishment of high-rise cityscape and compact urban settings is unavoidable (Hui, 2000).

A chronological classification of tall building types in Hong Kong can be observed. The typology includes the verandah type from the 1920s, the cantilevered living quarters type from the 1950-1960s, the rectangular mass type from the 1970s, and the podium type from the 1980s onwards. Among the rectangular mass type and podium type buildings, several shapes of building forms are observed such as the rectangular, "Y" shape, clusters and crucifix shapes. When observing the pattern of development at a district scale, two significant variations in development is observed, namely, the clusters of multiple intensive land use developments around the mass transit nodes and the linear multiple intensive land use development alongside main roads and streets in the older parts of Hong Kong.

The cluster of a high-density Multiple Intensive Land Use (MILU) ${ }^{2}$ development is mainly observed along (under) the three main rail lines of mass transit railway, namely, the Airport Railway, Urban Lines and Tseung Kwan O Lines. They are three-dimensional distribution of density and land uses integrated by three parallel

\footnotetext{
${ }^{2}$ MILU is mixed use (multi functional) and high-density (intensive) development. The concept of MILU was formulated to tackle the problems of urban sprawl and the development of dysfunctions of urban, suburban and rural areas (Haccou, 2007).
} 


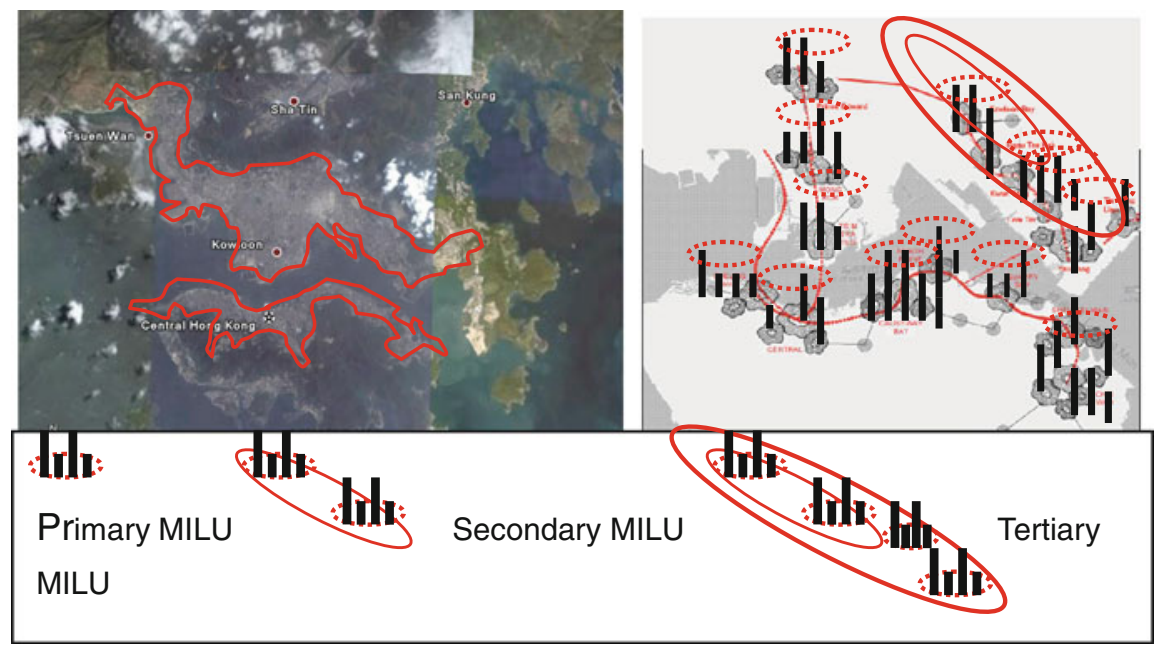

Fig. 3.1 Multiple intensive land use cluster development. Sources: Lau and Coorey (2007), and Wikipedia (2008)

commuting levels, namely, the mass transit rail (MTR), Kowloon-Canton railway, subways below ground, buses, taxis, light rail transit and tramways on ground and walkways above ground which are then vertically connected via ramps, stairways, elevators and escalators. Such developments are built above or connected in close proximity to mass transit railway and other public transport modes. As seen in Fig. 3.1, when several MILU nodes are developed in close proximity, an interdependency is formed among these developments where land use functions and services are shared, thus creating primary, secondary and tertiary interdependent zones (Lau et al., 2003).

Plot ratios, also known as Floor Area Ratios, of up to 15 for commercial uses and up to 10 for residential uses have led to buildings of up to 80 storeys built above 3-4 level podiums. The podium levels incorporate the secondary supporting functions such as commercial, recreational, government, institutional and community (GIC) land uses while the primary residential, office or hotels/serviced apartments are located above as seen in Fig. 3.2.

Four major types of MILU developments can be discerned according to its mix of land use types:

1. The primary use being office and/or hotel/serviced apartments with supporting secondary commercial, GIC and transport uses;

2. Primary use being residential supported by secondary commercial, GIC and transport uses;

3. Primary use being both residential and office supported by secondary commercial, GIC and transport uses;

4. Primary uses being office, residential, hotel/serviced apartments and secondary commercial, GIC and transport uses. 


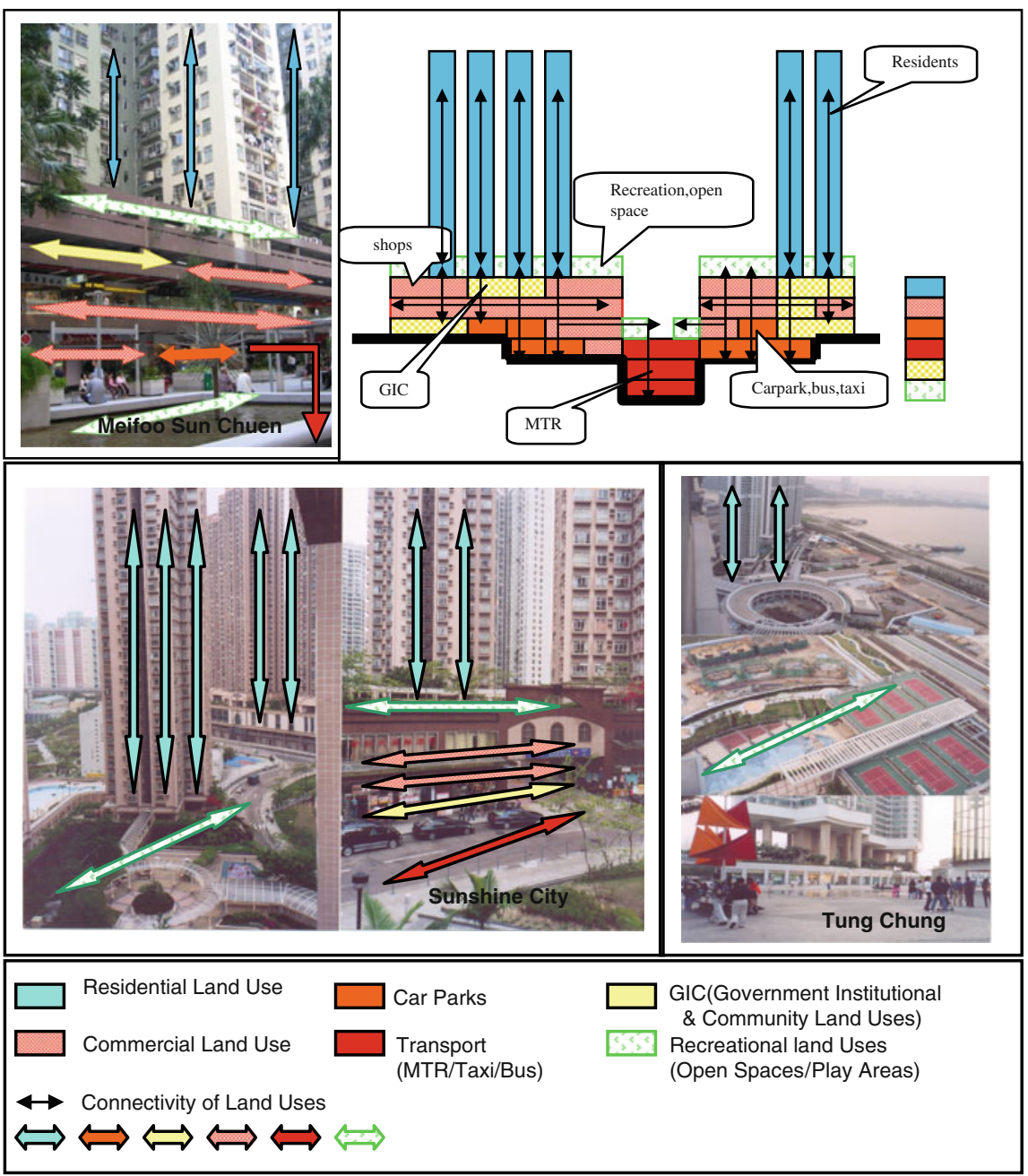

Fig. 3.2 Multiple intensive land use cluster development. Source: Lau and Coorey (2007)

These development clusters are defined as primary MILU nodes (Lau et al., 2003). Table 3.1 illustrates some examples of the four types of primary MILU developments that are commonly seen in Hong Kong.

In Hong Kong where the buildable land resources are scarce due to hilly terrain and scarcity of usable land, tall buildings serve as an optimal option to maximise development potentials and best returns. Reduction in travel time due to intensification of mixed land uses contributes to efficiency and economic viability of the city (Wu, 2005). The concept of home-work-play gives the residents efficiency, convenience and savings in time. Tall buildings also provide a heuristic device to meet the housing demands for the increasing population. Additionally, the mixed use 
Table 3.1 Four combinations of MILU developments in Hong Kong. Sources: Hong Kong Mass Transit Railway Corporation (2008), Wikipedia (2008), Google Earth (2008)

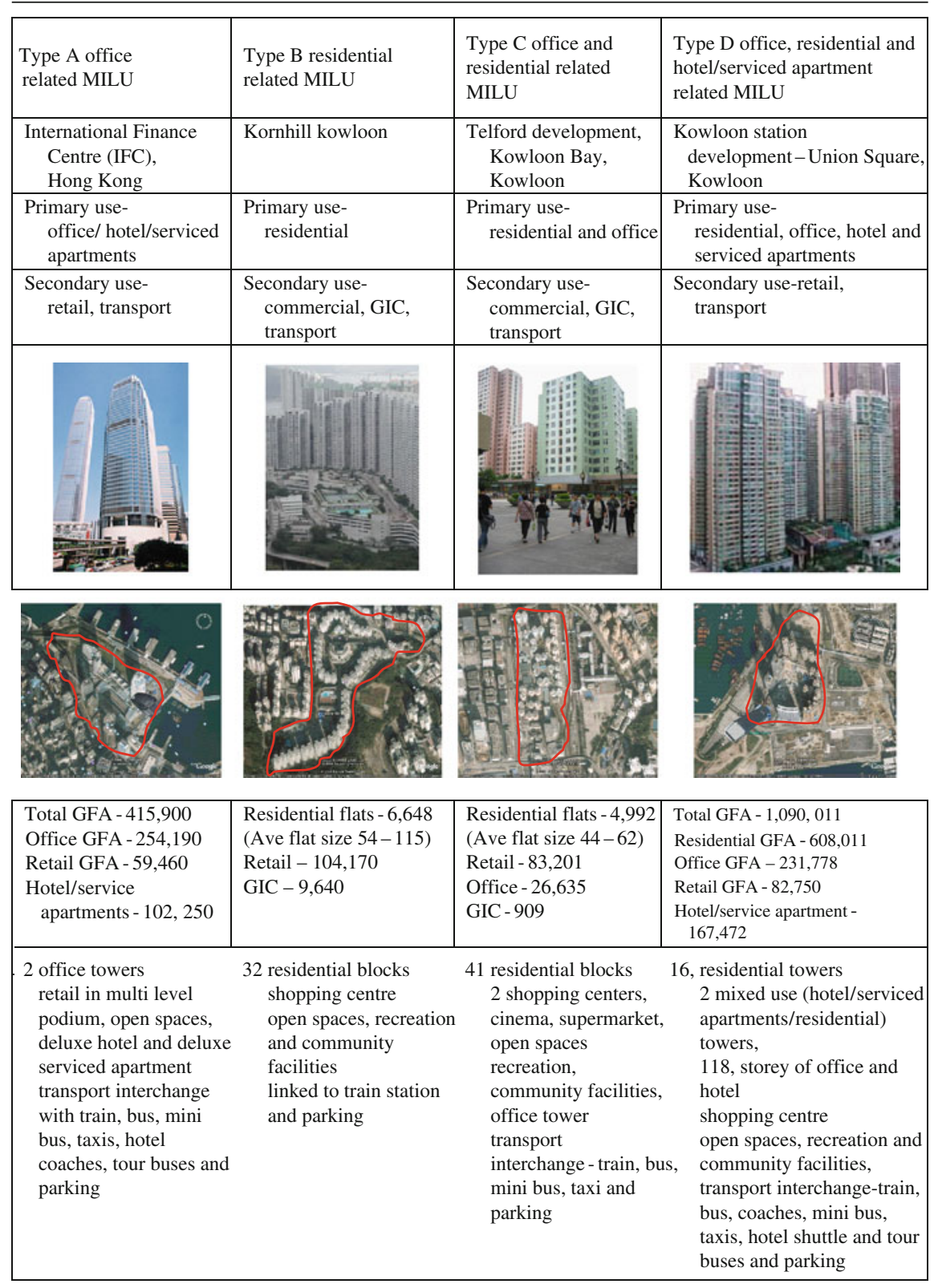


nature of developments creates places that are active and lively for longer duration of time, providing safe neighbourhoods and additional time for use of urban spaces for its residents. Rich, vibrant urban spaces are created within neighbourhoods. Urban intensification and compactness also provides savings in infrastructure and services, and high penetration of infrastructure and services for all residents. For example, it results in an overall reduction in energy use and traffic fumes (Wu, 2005).

High-rise building rather than urban sprawl reduces the use of woodlands and forest areas for development, saving valuable land resources for future use and recreation purposes. In Hong Kong such country parks and woodlands can be easily accessed. Yet, there are some consequences associated with tall residential built forms arising from the very high population and extreme density. Both social and environmental implications are prevalent in such conditions. This chapter is specifically focused on the environmental implications and various measures and solutions that may mitigate the environmental consequences of tall residential buildings taking Hong Kong as a case study.

\subsection{Environmental Challenges Related to Compact High-Rise Built Form}

High-density living in Hong Kong is strongly linked with significant air, water and noise pollution. Drastic environmental implications such as living in busy urban centres with high air and noise pollution, poor lighting and ventilation in individual housing units, urban heat island and wind tunnel effects are observed in Hong Kong's high-rise building developments. One of the problems related to mixed land use developments at very high intensities is the incompatibility of uses. This problem is particularly apparent in the old built-up areas because of a lack of comprehensive planning in the past (Fung, 2001). Examples include those residential developments that face environmental nuisance due to its location adjacent to industrial areas. Another example is where highways pass through residential areas, posing the threat of noise and air pollution.

Probably due to poor ventilation and lighting conditions, as high as $50 \%$ of all electricity used in Hong Kong is for lighting and space conditioning (Wu, 2005). Air conditioning accounts for one-third of the total power consumption of Hong Kong each year and costs HK\$10 billion (Ching, 2005). High space conditioning further aggravates the outdoor climate conditions creating a vicious cycle of environmental pollution such as urban heat island. Table 3.2 outlines the positive and negative effects of high density on city's energy demand as identified by Hui (2000).

Current air pollution levels in Hong Kong are high due to the high intensity of emissions from industry and traffic as well as a lack of proper environmental planning in the past. The number of motor vehicles is increasing due to population growth and demands. Many areas in Hong Kong are topographically confined by hills and the air pollution dispersion in these areas is inhibited (Hong Kong 
Table 3.2 Positive and negative effects of urban density on city's energy demand. Source: Hui (2000)

\begin{tabular}{|c|c|}
\hline Positive effects & Negative effects \\
\hline $\begin{array}{l}\text { Transport } \\
\text { - Promote public transport and reduce the } \\
\text { need for, and length of, trips by private cars }\end{array}$ & $\begin{array}{l}\text { Transport } \\
\text { - Congestion in urban areas reduces fuel } \\
\text { efficiency of vehicles }\end{array}$ \\
\hline $\begin{array}{l}\text { Infrastructure } \\
\text { - Reduce street length needed to accommodate } \\
\text { a given number of inhabitants } \\
\text { - Shorten the length of infrastructure facilities }\end{array}$ & $\begin{array}{l}\text { Vertical Transportation } \\
\text { - High-rise buildings involve lifts, thus } \\
\text { increasing the need for electricity for the } \\
\text { vertical transportation }\end{array}$ \\
\hline $\begin{array}{l}\text { such as water supply and sewage lines, } \\
\text { reducing the energy needed for pumping }\end{array}$ & $\begin{array}{l}\text { Ventilation } \\
\text { - A concentration of high-rise and large }\end{array}$ \\
\hline $\begin{array}{l}\text { Thermal Performance } \\
\text { - Multistory, multiunit buildings could reduce }\end{array}$ & $\begin{array}{l}\text { buildings may impede the urban } \\
\text { ventilation conditions }\end{array}$ \\
\hline $\begin{array}{l}\text { the overall area of the building's envelope } \\
\text { and heat loss from the buildings } \\
\text { - Shading among buildings could reduce solar } \\
\text { exposure of buildings during the summer }\end{array}$ & $\begin{array}{l}\text { Urban Heat Island } \\
\text { - Heat released and trapped in urban areas may } \\
\text { increase the need for air conditioning }\end{array}$ \\
\hline period & Natural Lighting \\
\hline $\begin{array}{l}\text { Energy Systems } \\
\text { - District cooling and heating system, which is } \\
\text { usually more energy efficiency, is more } \\
\text { feasible as density is higher }\end{array}$ & $\begin{array}{l}\text { - The potential for natural lighting is generally } \\
\text { reduced in high-density areas, increasing the } \\
\text { need for electric lighting and the load on air } \\
\text { conditioning to remove the heat resulting } \\
\text { from the electric lighting }\end{array}$ \\
\hline $\begin{array}{l}\text { Ventilation } \\
\text { - A desirable air flow pattern around buildings } \\
\text { may be obtained by proper arrangement of } \\
\text { high-rise building blocks }\end{array}$ & $\begin{array}{l}\text { Use of Solar Energy } \\
\text { - Roof and exposed areas for collection of } \\
\text { solar energy are limited }\end{array}$ \\
\hline
\end{tabular}

Planning Department, 2006a). Hong Kong has been facing two air pollution issues: local street-level pollution caused by motor vehicles; and regional smog problem caused by motor vehicles, industry and power plants both in Hong Kong and in the Pearl River Delta.

Street level pollution is mainly caused by the large number of motor vehicles in highly dense urban areas. The emissions are trapped in between the very tall buildings along the streets. The tall stacks of building towers create urban walls that are barriers to wind circulation and vistas in the city. Further, it causes wind tunnel effects and unsafe environments at street levels. Walking at street levels in compact cities is no longer safe for the pedestrian. The high flow of vehicular traffic damages the quality of the street environment, with their high noise and air pollutants. Therefore, whether within enclosed spaces or outside in the public areas and streets, the quality of the living environment is being damaged, affecting the overall quality of life.

Furthermore, since 2006, there has been an increasing concern on the "wall effect" caused by uniform high-rise developments, which adversely impact air circulation. A survey carried out by the environmental group, Green Sense revealed that 104 of 155 housing estates surveyed have a "wall-like" design (Yueng, 2006). 
The survey found the estates of Tai Kok Tsui and Tseung Kwan O as the best examples of this kind of design. In May 2007, citing concern over developments in West Kowloon, and near Tai Wai Yuen Long railway stations, some legislators called for a law to stop developers from constructing tall buildings which adversely affect air flow in densely populated areas, but the bid failed (Wong, 2007). More recently, in December 2008, a protest against "wall-effect" for a dozen of current and planned constructions was held at Central Government Offices (Ng, 2008). These protesters were also concerned about the development plans for Nam Cheong and Yueng Long stations.

Tall buildings also pose threats to public safety and health in terms of easy spread of disease and viruses, fire risks and domestic accidents. Adequate ventilation and building maintenance are therefore an important issue for high-rise buildings in order to avoid the spread of disease and accidents associated with dilapidated structures (Wu, 2005). Study on residents' satisfactions and aspirations of high-rise living in Hong Kong shows that better view, less noise, better air quality are the major reasons for people to opt for high-rise living (Lau, 2002). The higher selling prices for apartments on higher floors are also attributed to better views, less noise and better environmental quality. This trend may seem to suggest that residents who choose living on higher floors are seeking an escape from the environmental problems since living on higher floors allows one to be further way from the city surface. But, opting for taller buildings alone may not be a solution to the problem.

\subsubsection{Air Quality, Wind Environment and Air Ventilation}

There exists a strong pressure from people to improve air quality and environment. The government has acknowledged this requirement and taken measures to improve the environment. For example, it has implemented vehicle emission and fuel standards, cleaner alternatives to diesel, emission inspection and enforcements such as controlling smoky vehicles, etc. and promoting vehicle maintenance and ecodriving. In his 2006-2007 policy address, the Chief Executive of Hong Kong has emphasized the importance of addressing these issues in order to secure sustainable development for future generations. He has outlined some of the measures,

To reduce air pollution, we have formulated the Pearl River Delta (PRD) Regional Air Quality Management Plan. This plan, prepared in partnership with the Guangdong Provincial Government, aims to achieve specific emissions reduction targets by 2010 . We have now set up a 16-station air quality monitoring network in the PRD. Based on the data collected, the PRD Regional Air Quality Index is released everyday on the Internet to keep the public informed of the actual regional air quality. The data collected will also help us assess the effectiveness of our pollution reduction measures ... In Hong Kong, we have imposed emission caps on power plants at Castle Peak, Black Point and Lamma Island. These emission caps will be progressively tightened to meet the 2010 emission reduction targets. (Chief Executive, 2006-2007).

In 2006, particulates and nitrogen oxides levels on the street have dropped by 13 and $19 \%$ respectively since 1999 . The number of smoky vehicles on the road has also reduced by about $80 \%$ (Environmental Protection Department, 2006). Increased 
use of mass transport and reduction in private car and taxi could help to reduce the air pollution levels caused by vehicular traffic. In addition to policy measures, urban design measures are suggested for improving air ventilation (Chinese University of Hong Kong, 2005; Hong Kong Planning Department, 2006b). Recent study identifies the following urban design issues as a means to a better quality and comfortable urban environment: lack of breezeways air paths; tall and bulky buildings closely packed causing undesirable wind breaks to urban fabric; uniform building heights resulting in wind skimming over the top of buildings and not being re-routed into the fabric; tight narrow streets not aligned with prevailing wind with tall buildings resulting in urban canyons; lack of urban permeability-with few open spaces, minimal gaps between buildings, excessive podium structures reducing air volumes at ground levels; large building blocks forming wind barriers; projections from buildings and obstructions on narrow streets and general lack of soft landscaping, shading and greenery as contributing to poor air ventilation and environmental quality in high-rise, compact built areas (Chinese University of Hong Kong, 2005; Hong Kong Planning Department, 2006b).

For better urban air ventilation breezeways in the forms of roads, open spaces, and low-rise building corridors are suggested to allow air penetration to inner parts of urbanized areas. Breezeways, roads, main streets and avenues should be aligned either parallel or $30^{\circ}$ to the prevailing wind directions. Open spaces must be linked and aligned to form unobstructed wind corridors with low-rise structures alongside them. Space between buildings must be maximized, especially in large sites with dense developments. The longer frontages of blocks may be aligned parallel to wind corridors, and non-built areas and setbacks may be introduced to further allow for good wind penetration. To maximise the penetration of sea breezes and land breeze water front sites may take special precautions to avoid blockages in wind paths (Chinese University of Hong Kong, 2005).

Street patterns, building heights, open spaces, density, and landscape will determine the air ventilation, solar radiation, day lighting and air temperature in compact high-rise built forms having implications on indoor and outdoor environmental quality. To illustrate, reference is made to the natural ventilation study conducted for a proposed luxury residential development in Shenzhen, China. An assessment of air flow, solar energy and daylighting is done using computer based simulation tools such as Airpak (USA), ECOTECT (UK) and RADIANCE (USA) (Lau \& Li, 2006). Table 3.3 shows the airflow study and wind velocities within the compact high dense residential site.

All three graphs in Table 3.3 show high age of air, indicating low ventilation and increased stagnated air. In the surrounding areas of the high-rise towers the age of air reduces when elevation height increases from 5 to $40 \mathrm{~m}$, indicating better ventilation and cleaner air in the upper floors. The low age of air is also spread in larger proportions when the elevation height increases. As seen in the graphs, both low- and high-rise buildings form a wall that is oriented perpendicular to the prevailing wind patterns. This creates a barrier to the southeast winds and creates stagnant air in the leeward sides of the buildings. Ideally, these built forms must be oriented parallel to the prevailing wind direction to ensure better ventilation and cleaner air. Lower age of air and better ventilation is observed surrounding the smaller fragmented 
Table 3.3 Ventilation study of a low rise \& high rise new housing development in a Chinese city in Shenzhen, China. Source: Lau and Li (2006)

Natural ventilation (South-East wind)

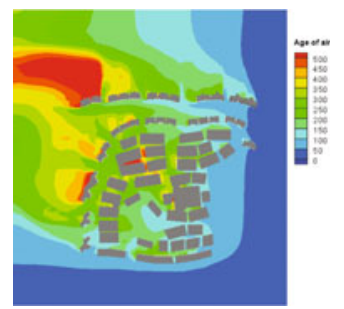

$\mathrm{H}=5 \mathrm{~m}$ (age of air)

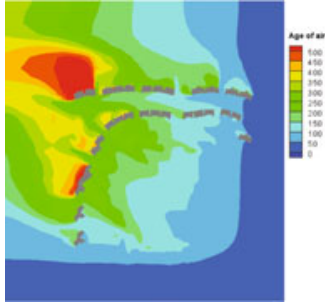

$\mathrm{H}=20 \mathrm{~m}$ (age of air)

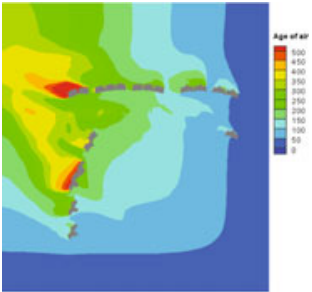

$\mathrm{H}=40 \mathrm{~m}$ (age of air)

Grey areas denote built areas. The large rectangular blocks in the S-E of the diagram are a low rise development. The two rows of smaller grey blocks in the $\mathrm{N}-\mathrm{W}$ of the low rise development is a high rise development. Smaller narrow grey blocks in the N-W denote a high rise development. The blue areas in the above graphs denote low age of air indicating well ventilated areas with fresh air. The red parts denote high age of air indicating less ventilated areas with stagnant air. Red, orange, yellow, green, light blue, blue and dark blue denote age of air in descending order



$\mathrm{H}=5 \mathrm{~m}$ (velocity)

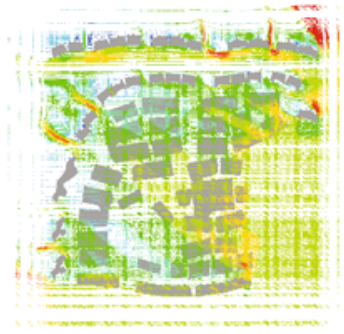

$\mathrm{H}=20 \mathrm{~m}$ (velocity)

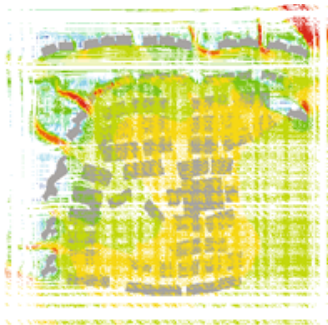

$\mathrm{H}=40 \mathrm{~m}$ (velocity)

In the three diagrams above concentrated areas denote higher wind velocities. The short arrow strokes indicate low and long arrow strokes indicate high velocities. The red, yellow, green and blue strokes denote wind velocity in descending order

building shapes and footprints. The areas surrounding larger blocks show high age of air and comparatively poor ventilation. In all three graphs, the row of high-rise building further away from the wind direction have a higher age of air spread in larger compositions compared to the row of buildings closer to the wind direction.

Observations confirm that the block size, orientations, building heights and distance from wind source affect the age of air, ventilation and air quality surrounding those buildings especially on the leeward side. The analysis can be further substantiated by the qualitative data gathered among occupants in high-rise living in Hong Kong (Lau, 2002). The general conceptions of occupants are that the apartments in higher floors are preferred due to better quality of environment - such quality can be specifically referred to as the air quality and reduced noise levels. 
The wind velocity graphs further confirm the observations made on the age of air distributions at varying heights. Lower wind velocities are observed at low height levels. Low wind velocities are also observed in the leeward sides of high-rise buildings, causing high age of air, poor ventilation and air quality in those areas. Also, when the distance from wind source increases, the velocities decrease indicating the higher age of air surrounding built forms further away from the wind source.

In order to enhance the wind environment in Hong Kong, an air ventilation issue has been included in the Hong Kong Planning Standards and Guidelines. A set of qualitative guidelines and a framework for carrying out air ventilation assessment have been formulated on the basis of the air ventilation assessment study recommendations. The guidelines incorporated in the Hong Kong Planning Standards and Guidelines are to strengthen the urban design guidelines for better air ventilation. The guidelines were developed according to the results of "Feasibility Study for Establishment of Air Ventilation Assessment System" (the AVA Study) was conducted and completed in 2005.

In addition to the guidelines, a technical guide for air ventilation assessment (AVA) has been issued by the Planning Department of Hong Kong (2005). AVA can be used to compare the air ventilation impacts of different design options and to identify the potential problem areas for design improvements. This technical guide specifies three steps in conducting AVA, i.e. expert evaluation, initial study and detailed study. The expert evaluation is a qualitative assessment based on the guidelines provided in Hong Kong Planning Standards and Guidelines, while the initial study will refine the expert evaluation and the detailed study will conclude the AVA. The AVA technical guide recommends using wind tunnel as the tool for carrying out both initial and detailed study. However, the use of Computational Fluid Dynamic (CFD) will be permitted in the initial study (Hong Kong Planning Department, 2005).

The examples of using CFD simulation in AVA study are presented in Table 3.4. This study highlighted the air ventilation benefits of raising the podium level of residential buildings. The table shows the comparison of mountain and valley breezes for base case and proposed designs.

According to the mountain/valley breeze simulations, we can find that the mountain can create local winds that vary from day to night if there is no background wind, which can also increase the air flow around the buildings in the mid-level. During the daytime, the air near the mountain surface can be heated up and higher than the free air far away at the same height due to the solar radiation. Thus the warm air moves up along the slopes. While during the night-time, as the mountain surfaces cool down, the cold breezes can be formed and flow down the slopes. The proposed new podium can enhance the air flow through the building. It can be imagined that the building region can benefit from the mountain breezes by bringing the cooled air at night-time on hot days. The thermal environment can be improved and energy can be saved (Li \& Yang, 2008). 
Table 3.4 Building shapes and re-entrants. Source: Lau and Baharudin

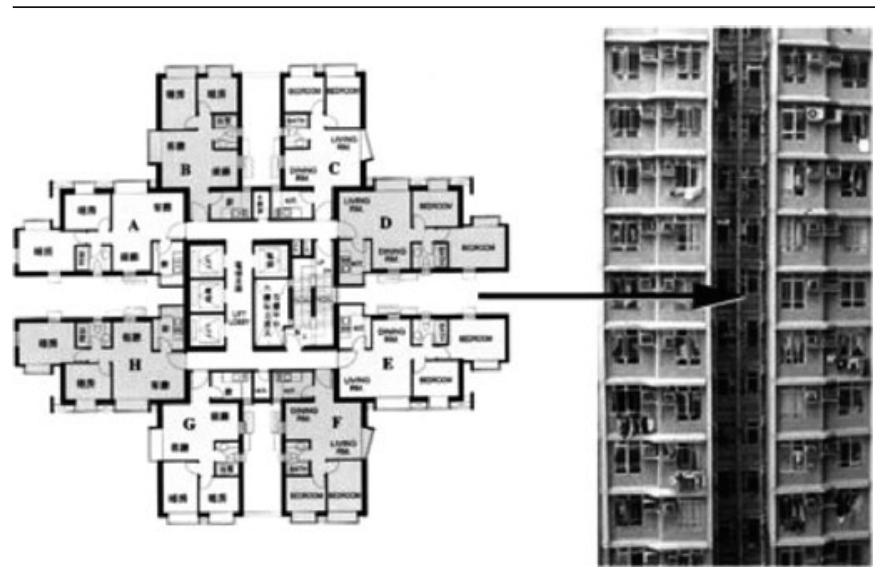

Prevailing layout plan prior to year 2003. Narrow and deep re-entrant shapes bring in minimal light and ventilation in the well type shape high-rise towers. This is also the typical shape of Amoy Gardens Residential Development where the outbreak of SARS occurred in March 2003. By April 2003 there were a total of 321 cases of SARS in Amoy Gardens (Hong Kong Department of Health, 2003)
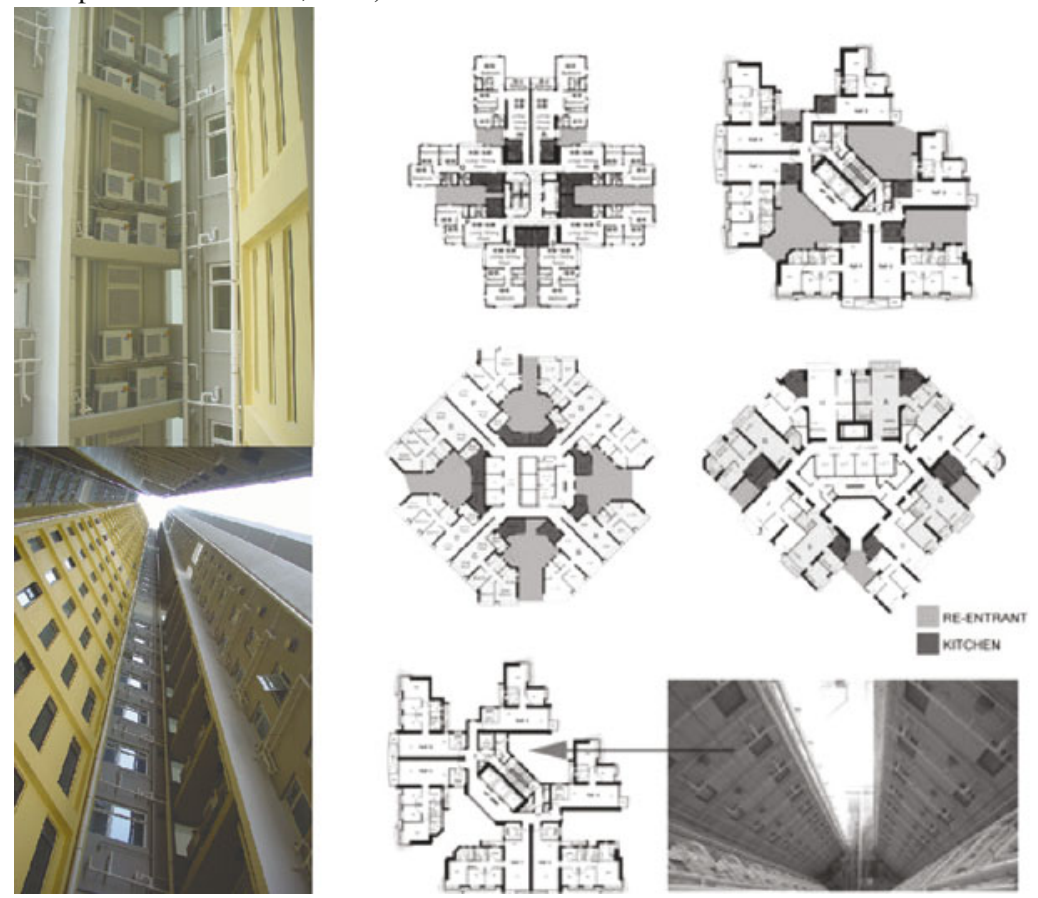

New layout plans after year 2003. Different re-entrant shapes are seen above creating shallow wider shaped reentrants. Better light and ventilation is created for better environmental quality and hygiene 


\subsubsection{Daylighting and Ventilation Within High-Rise Housing Units}

The air ventilation and daylight penetration into individual housing units play an important role in high-rise residential building designs. Many factors determine the daylight quality within housing units. Study done by the students of the final year Bachelor of Arts in Architectural Studies, Department of Architecture University of Hong Kong (2006/2007) reveals several factors that determine the daylight quality within housing units. Table 3.5 illustrates the types of building footprints found in high-rise residential buildings in Hong Kong and the evaluation of the lighting quality within a selected individual housing unit. A qualitative appraisal of the lighting quality in individual rooms of the housing unit is done by its occupant. This is combined with a quantitative - daylight simulation for the residential units showing the distribution of lighting within the spaces.

The distribution of lighting quality significantly varied across the building types and spaces/rooms within the individual units. Lack of sufficient lighting and ventilation in the kitchen and washrooms were a common observation. Obstructions to light due to windows being covered for better privacy and furniture layout were also observed as barriers to daylighting within the spaces. Some spaces have no windows at all and may be for the purpose of storage. But due to the lack of sufficient living space such spaces are also used for habitation. On most occasions, occupants use artificial lighting in such spaces even during day-time. Small window sizes and fixed glazing were also commonly noted as causes for poor light and ventilation.

Further, it can be observed that most kitchen and toilet spaces in high-rise buildings are ventilated via "Re-entrant light wells". These are equivalent to a light well with the main purpose of bringing in light and ventilation (Lau et al., 2006). Residents most often use the window opening into re-entrants for drying clothes, etc. The inlet and outlet water pipes to kitchen and toilets are located along the re-entrant spaces. The mechanical ventilation outlets are also located along these re-entrants that act as a shaft for bringing in fresh air as well as outlets for foul air from toilets and kitchen. The building shapes play a major role in determining the re-entrant shapes (see Table 3.5 for building shapes and re-entrant shapes). Most often, the reentrants are too narrow and inadequate for bringing in light and ventilation. Wider, more open re-entrant shapes are needed for sufficient light and ventilation.

The size, number and positioning of windows, the floor area of space, windowfloor area ratio, the shape of the room and depth of space from window, internal reflectance of materials and finishes, the building footprint shape, external obstructions, building orientation, obstructions caused by neighbouring towers and distance between towers, external barriers to wind and daylight such as hills and internal furniture layouts all affect the quality of ventilation and daylighting within residential units in high-rise towers (Final Year Bachelor of Arts in Architectural Studies Students, 2006/2007; Lau et al., 2006). A common issue is windows placed within the visibility range from neighbouring blocks cause lack of privacy. As a result, most windows are kept closed and covered using opaque materials such as shades, curtains, etc. blocking light and ventilation into the housing units. Tables 3.6 and 3.7 illustrate the case studies and respective daylight analyses. 
Table 3.5 Daylight study of high rise housing. Sources: Chan (2006/2007), Chow (2006/2007), Ho $(2006 / 2007)$

\begin{tabular}{|c|c|c|c|}
\hline Description & Well type & Cluster shape & Crucifix shape \\
\hline Location & $\begin{array}{l}\text { Full wing building, Hung } \\
\text { Hom, Kowloon }\end{array}$ & $\begin{array}{c}\text { Whampoa garden, } \\
\text { Kowloon }\end{array}$ & Lok Fu estate, Kowloon \\
\hline Ariel view & & & \\
\hline
\end{tabular}
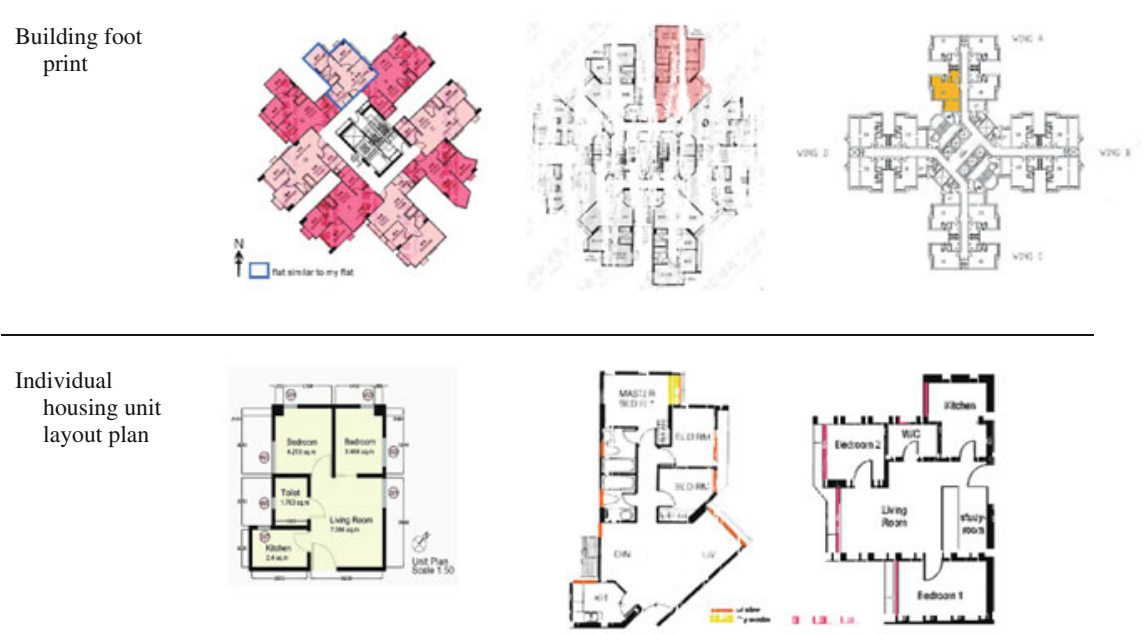

Uni: Plan (1:50)

Daylight analysis
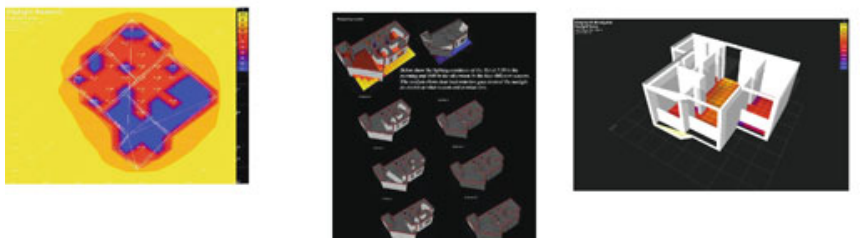

Issues relating to lighting and ventilation
Uneven day light distribution in several spaces within the block is caused due to window sizes and numbers, the floor area, window-floor area ratio, the location of windows, shape of building foot print, interior furniture layout and distance between blocks and block layout, contextual barriers such as hills, obstructions from other buildings also determine the lighting quality and ventilating inside housing units of high rise blocks. Windows facing neighbouring blocks are being constantly kept closed due to lack of privacy, thereby does not serve the purpose of brining in light and ventilation 
Table 3.6 Day light study of high rise housing. Sources: Chan (2006/2007), Cheung (2006/2007), Kei (2006/2007), Wong (2006/2007)

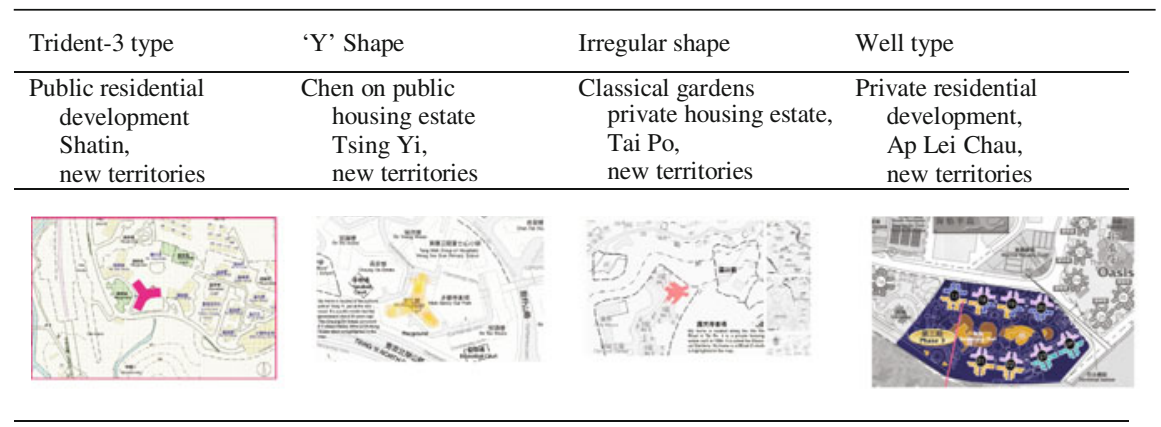
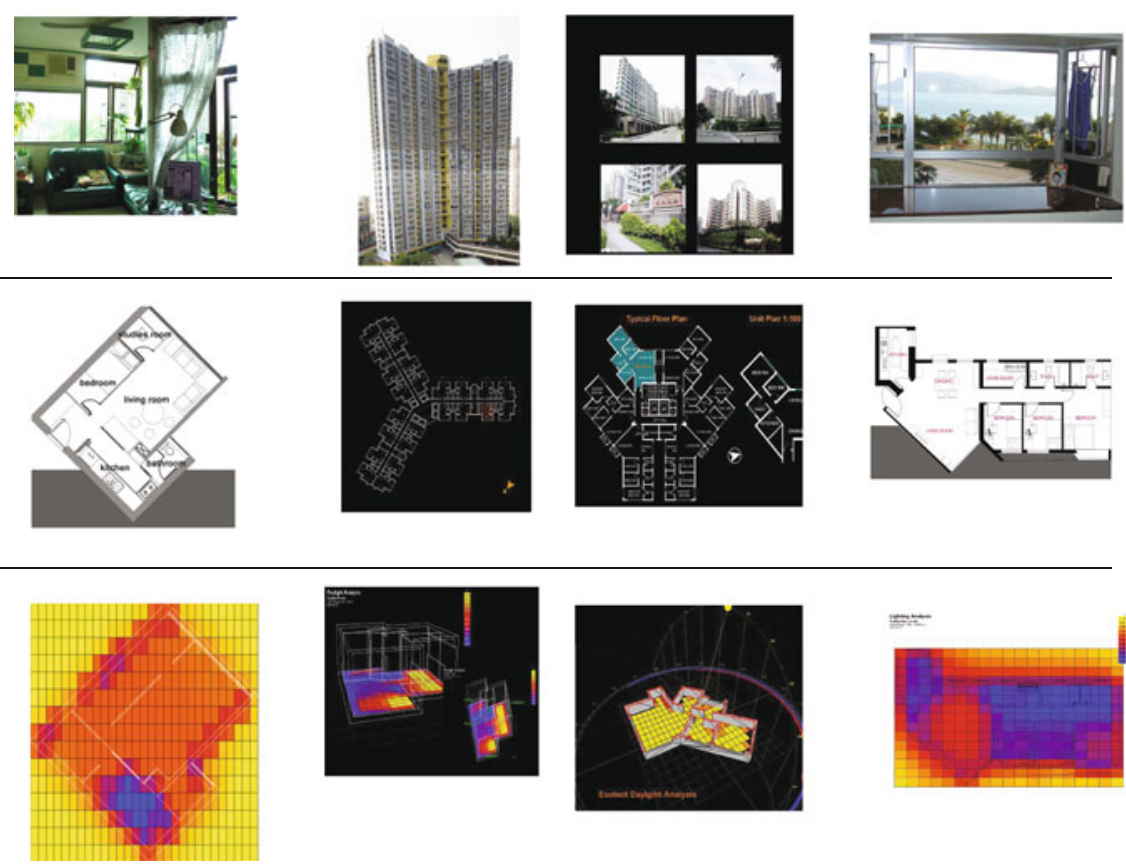

Deeper spaces from the window have less lighting

Bay windows and full height windows affect better lighting quality in the internal spaces

In addition, Lau and Baharuddin (2006) investigated the effect of relaxation of room height as a means for improving daylight conditions. The study investigated the relaxation of room heights from 2,800 to $3,650 \mathrm{~mm}$ and sustainable design features of proposed residential building located at Mid-Levels, Hong Kong. 
Table 3.7 Day light study for residential development in mid-levels, Hong Kong - the effects of relaxation of room height. Source: Lau (2006)

\begin{tabular}{lll}
\hline Case 1 - base case & Case 2-room 1 & Case 3-room 2 \\
\hline Window size- $1,250 \times 1,200 \mathrm{~mm}$ & Window size- $1,250 \times 1,200 \mathrm{~mm}$ & Window size- $1,250 \times 1,700 \mathrm{~mm}$ \\
Room height- $2,600 \mathrm{~mm}$ & Room height- $3,450 \mathrm{~mm}$ & Room height- $3,450 \mathrm{~mm}$ \\
\hline
\end{tabular}

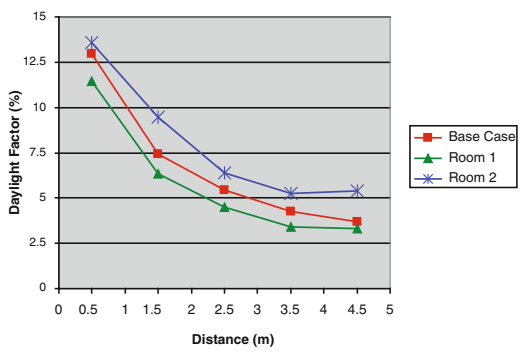

\footnotetext{
When window size remains the same and the room height is increased the day light within the room is improved but not a very significant improvement is seen. But when window size and room height is increased there is a significant increase in the daylight quality within the room. Also graph shows that in Room 2 with higher room height and larger window size the day light factor shows significant increase
}

The simulations were carried out based on the parameters: date 21 Dec (winter solstice), time 9:00 am, sky condition: overcast sky, design sky 8,500 lux. This analysis is regarded as the worst-case scenario for daylight calculation. Three cases are presented in Table 3.8.

The study revealed that an increase in room height has some effect on improving the daylight quality within a room. In addition, the increase of window height can make a significant contribution to the daylight quality within the room. 
Table 3.8 Study of factors influencing occupants' satisfaction of open space in high density public housing in Hong Kong. Source: Coorey (2007)

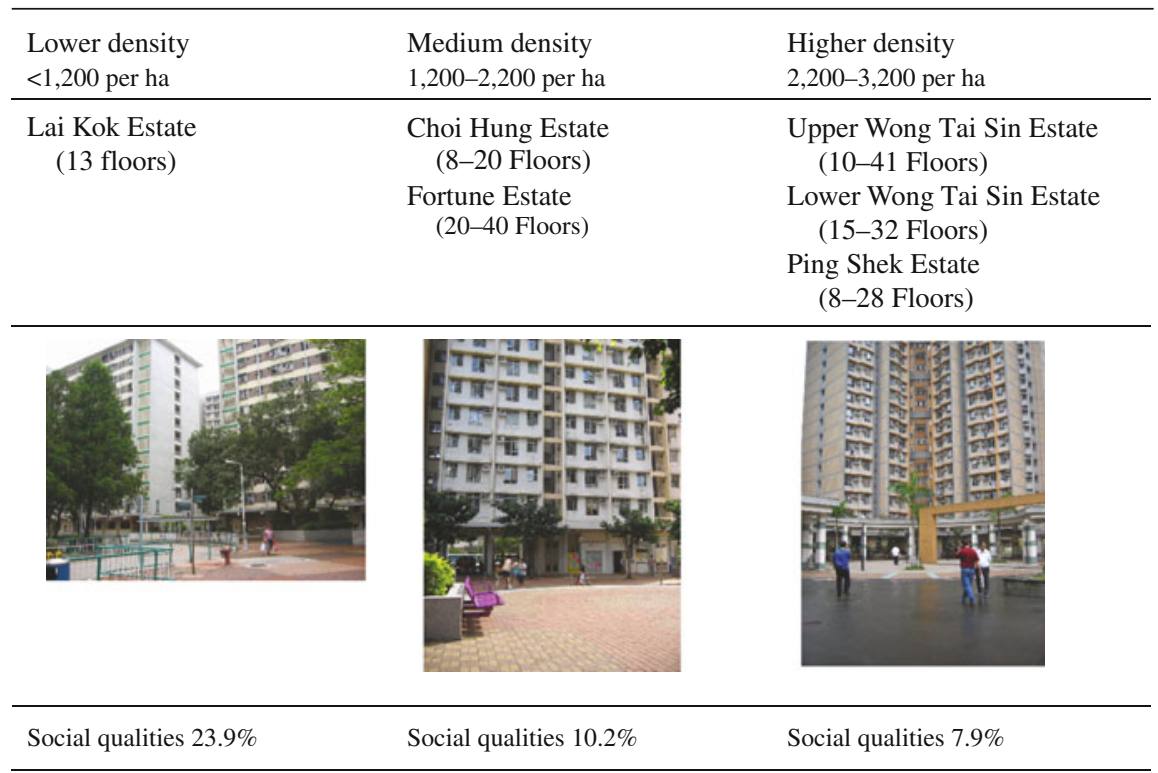

Physical qualities $10.5 \%$

Physical qualities $26.4 \%$

Physical qualities $17.7 \%$

Above results show that $23.9 \%$ variance in open space satisfaction is explained by the social quality of open space in the lower density cases, but in the higher density cases only $7.9 \%$ variance in open space satisfaction is explained by its social qualities

In contrast in the lower density cases only $10.5 \%$ variance in occupants' satisfaction of open space is explained by its physical qualities, but in the higher density cases $17.7 \%$ variance in satisfaction is explained by its physical qualities

In the above physical qualities the climatic comfort in open space (CLIMCOMF) is a significant indicator for open space satisfaction

\subsubsection{Occupants' Satisfaction of Open Space in Tall Residential Buildings}

Outdoor living space of high-rise residential buildings is equally important. Adequate provision of open space, greenery, vistas and visual corridors is a critical issue in the light of high land prices and the general lack of space between and around tall buildings. Open spaces and landscaping on podiums are design measures taken to improve resident perceptions of open spaces, views and greenery. Open spaces located close to highways, roadways, and transport nodes create poor environmental quality due to noise, dust and smoke emissions. In other words, it can be argued that even if open spaces are provided within residential blocks or outside in close proximity to homes, if its quality does not meet the demands and satisfaction of its users, such open spaces may not be efficiently utilised.

Podium open spaces and sky gardens create a barrier from traffic and pollution at road levels. Yet, being surrounded by high-rise buildings these spaces have a 
tendency to trap pollutants due to a lack of cross ventilation and high building mass. The lack of green cover, trees and hard landscaping may contribute to poor micro climatic conditions in the outdoor spaces of high-rise developments (Tan \& Fwa, 1992; Wilmers, 1990/1991). But, people are forced to use these open spaces despite its poor environmental quality. Study by Davies (1998) has shown that the most popular form of recreation among Hong Kong residents is the use of passive local open spaces. It is observed that the majority of users of such open spaces are elderly, low income groups whose accessibility to district open spaces and country parks may be limited.

Study of open space satisfaction among occupants of high-rise public residential estates in Hong Kong by Coorey (2007) shows that satisfaction of open space is primarily dependent on the physical qualities as opposed to its social qualities. The physical qualities such as climatic comfort, maintenance, facilities and provisions were identified as having important implications on their overall satisfaction. The study involved 600 questionnaire interviews conducted in 6 high-density public housing estates in Hong Kong. Respondents evaluated the physical and social quality of open space and their levels of satisfaction in 15 open spaces including those on podiums and ground level in the six high-rise developments.

A comparison of open spaces located within public housing of varying density showed that occupants in higher density developments considered the physical qualities of open space such as climatic comfort, provision for open space and maintenance as having higher impact on their overall open space satisfaction. Respondents living in the lower density cases tend to consider the social qualities such as safety, crowding, privacy and interaction to have a higher implication on their open space satisfaction (Coorey, 2007). The study highlighted the importance of environmental quality for optimum satisfaction of open spaces located within high-rise residential developments. It further highlighted that open space satisfaction among occupants living in higher density cases was significantly influenced by its environmental quality as opposed to its social qualities.

Such open spaces play a critical role in the lives of residents living in high-rise buildings as they are their only means of escape from the otherwise built up urban setting. Additionally, its importance for the elderly and low-income groups, specifically draws on the need for optimizing the environmental quality of open spaces in high-rise developments. An increase in respondents' satisfaction with climatic comfort in open space is shown when the number of trees, the proportion of greenery is higher and the sky view factor is low due to taller buildings adjacent to smaller narrower open spaces (Coorey, 2007).

\subsubsection{Noise Pollution}

Noise pollution is a common environmental quality issue associated with mixed use and high connectivity with transport networks. Taller buildings with residences in the higher floors are preferred due to less noise in the higher floors (Lau, 2002). Also, elevated walkways and podiums serve as design principles for segregating 
pedestrian routes from noise and pollutant sources at street and ground levels. The podiums act as buffers from noise at ground level. The building clusters in Hong Kong are well integrated through elevated walkways subways and podiums that induce people to walk through buildings rather than being exposed to the fumes and noise of vehicular traffic at road levels.

Study of external noise measurements in the surrounding areas of an arts performing school showed that high traffic noise reflectance was caused by the façade effect and canyon effect due to high-rise built forms running parallel to the roadways (Lau, 2006). Measurements were taken alongside two roadways on opposite sides of the arts school. One roadway has high-rise buildings located alongside it while low-rise buildings frame the roadway on the opposite side. Higher noise levels are observed from the roadway with high-rise buildings. The facades of high-rise built form act as reflectors for noise sources from vehicular traffic. The taller building forms create a canyon effect causing higher noise levels.

It can be suggested that the building facades, orientations with the noise sources and its noise reflectance and absorption values must be manipulated. This can be done by orientating the buildings so that it does not obstruct and reflect noise. Instead, it disseminates the noise and avoids a canyon effect. The materials of the facades should be of less reflectance and higher absorption values. In addition, trees and shrubs can be introduced as noise screens alongside roadways. Zoning at planning stage must be done with an awareness of the noise sources and noise reflectors in the surrounding context. Habitable spaces can be buffered by elevating the units above the noise source levels. Soft landscaping features such as water fountains can be used to mask and create distraction from traffic noise.

\subsection{Conclusion}

Although tall residential buildings have many social and environmental implications, Hong Kong's topography and continuous increase in population have propelled the planning and design of Hong Kong's built form clearly in the direction of tall buildings. But how tall and how to design such tall building is the question of concern. The general policy and regulations provoke taller buildings. But the regulations and attention of Hong Kong designers are turned towards more sensitive design measures that will balance the demand for taller buildings with more sensitive, sustainable and liveable design features. The critical implications for building tall are mainly associated with poor air quality, lack of wind ventilation in a macro context of a high-rise city as well as the micro context within the residential units or apartments.

Poor daylighting quality within tall buildings is a pressing issue for tall buildings. The lack of open space and the poor environmental quality in such open space is another issue that impacts the quantity and quality of open space among highrise occupants. The noise levels due to reflectance from high-rise towers caused by façade and canyon effects are also a challenge for zoning, orientations and design. 
Such issues bring about specific criteria for zoning, planning and design in tall building contexts. This chapter highlighted some of the design issues and possibilities.

Acknowledgments The author acknowledges the research assistance given by Dr. Shaleeni B. A. Coorey and Dr. Baharuddin of Department of Architecture, the University of Hong Kong. The useful information and data provided by Professor Y. Li and Dr. Lina Yang of Department of Mechanical Engineering, the University of Hong Kong, the Chinese University of Hong Kong- Air Ventilation Assessment Project Team, Hong Kong Planning Department, Hong Kong Buildings Department, Hong Kong Mass Transit Rail Corporation, and the Final Year Bachelor of Arts Students 2006/2007 of the Department of Architecture, University of Hong Kong; Chan K. H., Cheung H. F., Chow K. Y., Kei Y. S., and Wong Y. N. are gratefully acknowledged.

\section{References}

Burton, E. (2000). The compact city: Just or just compact? A preliminary analysis. Urban Studies, 37(11), 1969-2007.

Chan, K. H. (2006/2007). Daylight analysis: Residential buildings in Hong Kong. Unpublished Bachelor of Arts in Architectural Studies Final Year ProjectWork, Department of Architecture, The University of Hong Kong, Hong Kong.

Cheung, H. F. (2006/2007). Daylight analysis: Residential buildings in Hong Kong. Unpublished Bachelor of Arts in Architectural Studies Final Year ProjectWork, Department of Architecture, The University of Hong Kong, Hong Kong.

Chief Executive. (2006-2007). 2006-2007 policy address by chief executive. Hong Kong: Hong Kong SAR Government. Last accessed December 15, 2009, from http://www.info.gov.hk/gia/general/200610/11/P20061010101_print.htm

Chinese University of Hong Kong. (2005). Feasibility study for establishment of air ventilation assessment system-executive summary. Hong Kong: Department of Architecture, Chinese University of Hong Kong, Hong Kong.

Ching, L. Y. (2005). Sustainable development of tall buildings in Hong Kong. Paper presented at the tall buildings: From engineering to sustainability, Hong Kong.

Chow, K. Y. (2006/2007). Daylight analysis: Residential buildings in Hong Kong. Unpublished Bachelor of Arts in Architectural Studies Final Year ProjectWork, Department of Architecture, The University of Hong Kong, Hong Kong.

Coorey, S. B. A. (2007). Design of open spaces in high density zones: Case study of public housing estates in Hong Kong. Unpublished PhD thesis, The University of Hong Kong, Hong Kong.

Davies, L. (1998). Study of leisure habits and recreation preferences and review of chapter four of the Hong Kong planning standards and guidelines. Final Report, Planning Department, Hong Kong.

Final Year Bachelor of Arts in Architectural Studies Students - Department of Architecture University of Hong Kong. (2006/2007). Daylight analysis: Residential buildings in Hong Kong. Unpublished Final Year Project, The University of Hong Kong, Hong Kong.

Fung, B. C. K. (2001). Planning for high density development in Hong Kong. Hong Kong: The Planning Department of Hong Kong, Hong Kong.

Givoni, B. (1998). Climate consideration in building and urban design. New York: Van Nostrand Reinhold.

Google Earth. (2008). IFC, Kornhill, Telford, union square images in google earth. Last accessed December 15, 2009, from http://www.googleearth.com

Haccou, H. A. (2007). MILUnet: Multi functional intensive land use - Principle, practices, projects, policies - Towards sustainable area development. Harbiforum Foundation, The Netherlands.

Ho, K. Y. (2006/2007). Daylight analysis: Residential buildings in Hong Kong. Unpublished Bachelor of Arts Final Year Project Work, Department of Architecture, The University of Hong Kong, Hong Kong. 
Hong Kong Department of Health. (2003). Outbreak of severe acute respiratory syndrome (SARS) at Amoy Gardens, Kowloon Bay, Hong Kong - Main findings of the investigations. Department of Health, Hong Kong.

Hong Kong Environmental Protection Department. (2006). Air quality in Hong Kong 2006. Hong Kong Environmental Protection Department, Hong Kong. Last accessed December 15, 2009 , from http://www.epd-asg.gov.hk/english/report/files/aqr06e.pdf

Hong Kong Mass Transit Railway Corporation. (2008). MTR properties. Hong Kong Mass Transit Railway Corporation, Hong Kong. Last accessed December 15, 2009, from http://www.mtr.com.hk/eng/properties/prop_dev_index.html

Hong Kong Planning Department. (2005). Technical guide for air ventilation assessment for developments in Hong Kong. Hong Kong Planning Department, Hong Kong. Last accessed December 15, 2009, from http://www.pland.gov.hk/p_study/comp_s/avas/ papers\&reports/technical_guide.pdf

Hong Kong Planning Department. (2006a). Planning department annual report 2006. Hong Kong Planning Department, Hong Kong.

Hong Kong Planning Department. (2006b). Hong Kong planning standards and guidelines. Hong Kong Planning Department, Hong Kong.

Hui, S. C. M. (2000). Low energy building design in high density urban cities. World Renewable Energy Congress VI, Brighton.

Jenks, M. (2000). Sustainable urban form in developing countries? In M. Jenks \& R. Burgess (Eds.), Compact cities sustainable urban forms for developing countries. London: Spon Press.

Kei, Y. S. (2006/2007). Daylight analysis: Residential buildings in Hong Kong. Unpublished Bachelor of Arts Final Year Project Work. Department of Architecture, The University of Hong Kong, Hong Kong.

Lau, S. S. Y. (2002). A survey on residents' responses to high rise living in Hong Kong. Centre for Architecture and Urban Design for China and Hong Kong, Department of Architecture, The University of Hong Kong, Hong Kong.

Lau, S. S. Y. (2006). Traffic noise measurement for the school of performing arts. Department of Architecture, The University of Hong Kong, Hong Kong.

Lau, S. S. Y., \& Baharuddin. (2006). Sustainable building design: Residential development, midlevels, Hong Kong. The University of Hong Kong, Hong Kong.

Lau, S. S. Y., Baharuddin, Lee, W. Y. W., Leung, D. K. C., Ye, A. M., Amato, A., et al. (2006). Reconsidering daylighting design parameters for tall buildings in densely built city. Architectural Science Review, 49(3), 285-294.

Lau, S. S. Y., \& Coorey, S. B. A. (2007). Hong Kong: MILU and how it is perceived. In H. A. Haccou, T. Deelstra, A. Jain, V. Pamer, K. Krosnicka, \& W. R. De (Eds.), MILUnet: Multi functional intensive land use - Principle, practices, projects, policies - Towards sustainable area development. Harbiforum Foundation, The Netherlands.

Lau, S. S. Y., Ghiridharan, R., \& Ganesan, S. (2003). Policies for implementing multiple intensive land use in Hong Kong. Journal of Housing and the Built Environment, 18(4), 365-378.

Lau, S. S. Y., \& Li, Y. (2006). Environmental performance analysis: Proposed luxury residential development in Shenzhen, China. The University of Hong Kong, Hong Kong.

Li, Y., \& Yang, L. (2008). Ventilation study of residential development at IL 2510 \& extension, 15 magazine gap road, mid-levels, Hong Kong. Unpublished Report, The University of Hong Kong, Hong Kong.

Masnavi, M. R. (2000). The compact city in practice: The new millennium and the new urban paradigm. In K. Williams, E. Burton, \& M. Jenks (Eds.), Achieving sustainable urban form (pp. 64-73). London: E\&FN Spon.

Newman, P., \& Kenworthy, J. (1992). Is there a role for physical planners. Journal of the American Planning Association, 58, 353-362.

Ng, Y. H. (2008). Protesters demand review of 'wall effect' projects, South China morning post. Last accessed December 15, 2008, from http://proquest.umi.com/ 
Planning department of Hong Kong. (2005). Technical guide for air ventilation assessment (AVA) for developments in Hong Kong. Planning Department of Hong Kong, Hong Kong. Last accessed December 15, 2009, from http://www.pland.gov.hk/ pland_en/p_study/comp_s/avas/papers\&reports/technical_guide.pdf

Tan, S., \& Fwa, T. (1992). Influence of pavement materials on the thermal environment of outdoor spaces. Building and Environment, 27(3), 289-295.

Williams, K., Burton, E., \& Jenks, M. (2000). Achieving sustainable urban form. London: E\&FN Spon.

Wilmers, F. (1990/1991). Effects of vegetation on urban climate and buildings. Energy and Buildings, 15-16, 425-431.

Wong, Y. N. (2006/2007). Daylight analysis: Residential buildings in Hong Kong. Unpublished Bachelor of Arts Final Year ProjectWork. Department of Architecture, The University of Hong Kong, Hong Kong.

Wong, O. (2007). Call for law against 'wall effect' fails, South China morning post. http://proquest.umi.com/

Wu, M. (2005). Policies and planning of tall buildings in Hong Kong. Paper presented at the tall buildings: From engineering to sustainability, Hong Kong.

Xue, C. Q. L., Manuel, K. K., \& Chung, R. H. Y. (2001). Public space in the old derelict city area A case study of Mong Kok, Hong Kong. Urban Design International, 6(1), 15-31.

Yueng, C. (2006). Asia's walled city' leaves - Residents longing for air, the standard. Accessed December 15, 2009, from http://www.thestandard.com.hk/ 